\title{
Blockade of CTLA-4 and Tim-3 pathways induces fetal loss with altered cytokine profiles by decidual $\mathrm{CD} 4^{+} \mathrm{T}$ cells
}

Songcun Wang ${ }^{1}$, Chunqin Chen ${ }^{1}$, Mengdie Li ${ }^{1}$, Jinfeng Qiann', Fengyun Sun ${ }^{1}$, Yunyun Li', Min Yu ${ }^{2}$, Mingyan Wang ${ }^{3}$, Xingxing Zang ${ }^{4}$, Rui Zhu', Dajin $\mathrm{Li}^{1}$ and Meirong $\mathrm{Du}^{1}$

\begin{abstract}
The single and/or combination use of immune checkpoint blockade therapies in human infectious diseases and cancer are rapidly expanding. Despite early efforts, substantial uncertainty remains about the safety and efficacy of immune checkpoint blockade in some populations. Cytotoxic T-lymphocyte-associated protein 4 (CTLA-4) and T-cell immunoglobulin mucin-3 (Tim-3) are the major targetable co-inhibitory receptors on T cells. Here we showed that in animal studies, treatment with either CTLA-4- or Tim-3-blocking antibody caused greater susceptibility to fetal loss with altered cytokine profiles by decidual $\mathrm{CD} 4^{+} \mathrm{T}\left(\mathrm{dCD} 4^{+} \mathrm{T}\right)$ cells. CTLA-4 and Tim-3 pathways appeared to play key roles in maintaining maternal-fetal tolerance by regulating the function of $\mathrm{dCD} 4^{+} T$ cells. In addition, the abnormality in number and functionality of $\mathrm{dCTLA}-4^{+} \mathrm{Tim}-3^{+} \mathrm{CD} 4^{+} \mathrm{T}$ cells was associated with miscarriage. These findings underscored the important roles of the CTLA-4 and Tim-3 pathways in regulating $d C D 4^{+} T$ cells function and maintaining normal pregnancy. Our study also emphasized the importance of careful consideration of reproductive safety when choosing immune checkpoint blockade therapies in real world clinical care.
\end{abstract}

\section{Introduction}

$\mathrm{T}$ cell activation following antigen recognition requires a secondary co-stimulatory signal, which can be either positive or negative. Treatment with neutralizing antibodies that target inhibitory signals, or "checkpoint blockade" to enhance immune responses, has been proven as a promising therapeutic strategy for a variety of cancers and chronic viral infections ${ }^{1}$. Cytotoxic T-lymphocyteassociated protein 4 (CTLA-4), programmed death 1 (PD-1), and T-cell immunoglobulin mucin-3 (Tim-3) are

\footnotetext{
Correspondence: Meirong Du (dmrlq1973@sina.cn)

${ }^{1}$ Laboratory for Reproductive Immunology, NHC Key Lab of Reproduction Regulation(Shanghai Institute of Planned Parenthood Research), Shanghai Key Laboratory of Female Reproductive Endocrine Related Diseases, Hospital of Obstetrics and Gynecology, Fudan University Shanghai Medical College, Shanghai, P.R. China

${ }^{2}$ Reproductive Medicine Center, Hospital of Obstetrics and Gynecology, FudanUniversity Shanghai Medical School, Shanghai, P.R. China

Full list of author information is available at the end of the article. These authors contributed equally: Songcun Wang, Chunqin Chen Edited by $\mathrm{H}-\mathrm{U}$ Simon
}

the major targetable co-inhibitory receptors on $\mathrm{T}$ cells. The development of these immunotherapy agents has increased since the first approval of anti-CTLA-4 therapy (ipilimumab) by the United States Food and Drug Administration for melanoma in $2011^{2}$. Despite their success, the single use of currently approved antibodies was effective in only $20-30 \%$ of patients ${ }^{3}$. Currently, combination approaches against different targets seem to be effective for favorable clinical outcomes ${ }^{4}$. For example, CTLA- 4 had a role in both early and late stages of T cell activation and was mainly expressed on $\mathrm{T}$ cells residing in lymph nodes ${ }^{5}$, while Tim-3 could exert its function by regulating cell apoptosis ${ }^{6}$, so the combination of antiCTLA- 4 and anti-Tim- 3 could restore the greatest degree of $\mathrm{T}$ cell function.

During normal pregnancy, the semi-allogeneic fetus has the capacity to avoid immune attack by the maternal immune system, and the placenta is regarded as a pseudomalignant type of tissue ${ }^{7}$. Impaired tolerance induction or

\section{(c) The Author(s) 2018}

(c) (i) Open Access This article is licensed under a Creative Commons Attribution 4.0 International License, which permits use, sharing, adaptation, distribution and reproduction cc) in any medium or format, as long as you give appropriate credit to the original author(s) and the source, provide a link to the Creative Commons license, and indicate if changes were made. The images or other third party material in this article are included in the article's Creative Commons license, unless indicated otherwise in a credit line to the material. If material is not included in the article's Creative Commons license and your intended use is not permitted by statutory regulation or exceeds the permitted use, you will need to obtain permission directly from the copyright holder. To view a copy of this license, visit http://creativecommons.org/licenses/by/4.0/. 
excessive inflammation can lead to severe pregnancy complications such as recurrent spontaneous abortion (RSA), pre-eclampsia, or preterm delivery ${ }^{8}$. $\mathrm{T}$ cells, particularly $\mathrm{CD} 4^{+} \mathrm{T}$ cells, seem to play a pivotal role in inducing and maintaining maternal-fetal tolerance. Driven by a set of transcriptional regulators and cytokines, naive $\mathrm{CD} 4^{+} \mathrm{T}$ helper (Th) cells are able to differentiate into distinct subsets, including Th1, Th2, Th17, and Treg cells ${ }^{9}$. Treg expansion and a polarization toward Th2 bias in the maternal immune response have long been considered the main mechanisms of inducing tolerance toward the fetus ${ }^{8}$. Women who experienced RSA exhibited a marked Th1 bias ${ }^{10}$. The expression of the Th1-type cytokine TNF- $\alpha$ was observed in decidual tissues from failing human pregnancies, and this cytokine was shown to lead to the fetal loss in mice ${ }^{8}$. A lower IL-10 to IFN- $\gamma$ ratio was associated with abnormal pregnancy outcome in mice, and pregnancy outcomes were improved when Treg cells were transferred from the maternal-fetal interface ${ }^{11}$. Given the similarities between a tumor and a fetus, the effects of checkpoint blockade on the reproductive system and the role of co-signaling molecules in maternal-fetal immunity need to be explored.

A second anti-CTLA-4 monoclonal antibody (mAb), tremelimumab, displayed activity in early phase studies ${ }^{12}$. One anti-Tim-3 mAb (MBG453) was also being investigated in phase I-II clinical trial in patients with advanced malignancies; however, no clinical results have yet been reported $^{13}$. In the present study, efficacy studies of antiCTLA-4 and anti-Tim-3 were first done in mouse pregnancy models, and then the expression and function of CTLA-4/Tim-3 on $\mathrm{CD}^{+}{ }^{+} \mathrm{T}$ cells during normal pregnancy and miscarriage were explored. The current data demonstrates that combined blockade of the CTLA- 4 and Tim-3 pathways results in an increased fetal loss in an experimental mouse pregnancy model by altering the function of decidual $\mathrm{CD}^{+} \mathrm{T}\left(\mathrm{dCD} 4^{+} \mathrm{T}\right)$ cells. Furthermore, the co-expression of CTLA-4 and Tim-3 on $\mathrm{dCD} 44^{+} \mathrm{T}$ cells is important in Th2 bias and Treg expansion at the maternal-fetal interface, thereby, maintaining a normal pregnancy.

\section{Results}

\section{Effects of dual blockade of CTLA-4 and Tim-3 on mouse pregnancy}

In the first assay, we examined pregnant $\mathrm{CBA} / \mathrm{J}$ females challenged with CTLA4- and/or Tim-3-blocking antibody. Treatment with either blocking antibody caused a higher rate of embryo resorption (data not shown), decreased growth in body weight (Fig. 1a), and reduction in the number of live fetuses per uterus (Fig. 1b). Furthermore, dual blockade of the CTLA4- and Tim-3 pathways had a combined effect, leading to the greatest susceptibility to fetal loss (Fig. 1a, b). These data indicated that CTLA4- and Tim-3-blocking antibody had some side effects on the fertility of mice.

For the checkpoint blockade therapies involved in the regulation of $\mathrm{T}$ cell responses, we analyzed the function of $\mathrm{dCD} 4^{+} \mathrm{T}$ cells of treated mice to test whether the fetal loss following in vivo blockade of CTLA-4 and/or Tim-3 resulted from $\mathrm{CD} 4^{+} \mathrm{T}$ cell dysfunction. The production of Th1-type cytokines, TNF- $\alpha$, and IFN- $\gamma$, and Th1 specific transcription factor, T-bet, increased following single or combined antibody blockade (Fig. 1c). While the production of Th2-type and Treg-type cytokines and transcription factors decreased (Fig. 1d, e), treatment with anti-CTLA-4 and/or anti-Tim-3 antibody did not affect the expression of IL-17A and ROR- $\gamma \mathrm{t}$ during pregnancy (Figure S1).

\section{Blockade of CTLA-4 and Tim-3 affected the function of human $\mathrm{dCD} 4^{+} \mathrm{T}$ cells}

It was impossible to apply anti-CTLA-4 and/or antiTim-3 antibody in pregnant women because of ethical constraints. So, in vitro experiments were done using decidual cells obtained from the decidual tissue of normal pregnancies terminated for non-medical reasons. We stimulated $\mathrm{dCD} 4^{+} \mathrm{T}$ cells with anti-CD3/CD28 in the presence or absence of antibodies blocking CTLA-4/Tim3 pathways or combinations of blocking antibodies. After $48 \mathrm{~h}$, expression levels of intracellular cytokines and transcription factors in $\mathrm{dCD} 4^{+} \mathrm{T}$ cells were analyzed. Unlike the results observed in infection and cancer ${ }^{1}$, combinations of blocking CTLA- 4 and Tim- 3 increased the production of Th1-type TNF- $\alpha$ and IFN- $\gamma$, but had no effects on the expression of Th1 master transcription factor T-bet (Fig. 2a). Compared with the control group, anti-CTLA-4 or anti-Tim-3 antibody alone was enough to affect the production of Th2-type IL-4 and GATA-3, and this decrease was especially notable in the dual blockade of CTLA-4 and Tim-3 signals (Fig. 2b). As shown in Fig. 2c, the expression of TGF- $\beta 1$, IL- 10 and Foxp3 by $\mathrm{dCD} 4^{+} \mathrm{T}$ cells was also down-regulated following combined antibody blockade. However, CTLA-4 or Tim-3 blockade again had no effects on IL-17A production and ROR- $\gamma \mathrm{t}$ expression by $\mathrm{CD} 4^{+} \mathrm{T}$ cells at the maternal-fetal interface (Figure S2). Taken together with our in vivo data, dual blocking of CTLA-4 and Tim-3 pathways significantly abrogated Th2 and Treg-mediated fetal protection during normal pregnancy.

\section{Expression of CTLA-4 and Tim-3 on $\mathrm{CD} 4^{+} \mathrm{T}$ cells during early pregnancy}

We examined the expression of CTLA-4 and Tim-3 on $\mathrm{CD} 4^{+} \mathrm{T}$ cells during the early pregnancy in humans to investigate their potential roles in maternal-fetal immunity. As shown in Fig. 3a, CTLA-4 and Tim-3 were expressed in significantly higher proportions of 


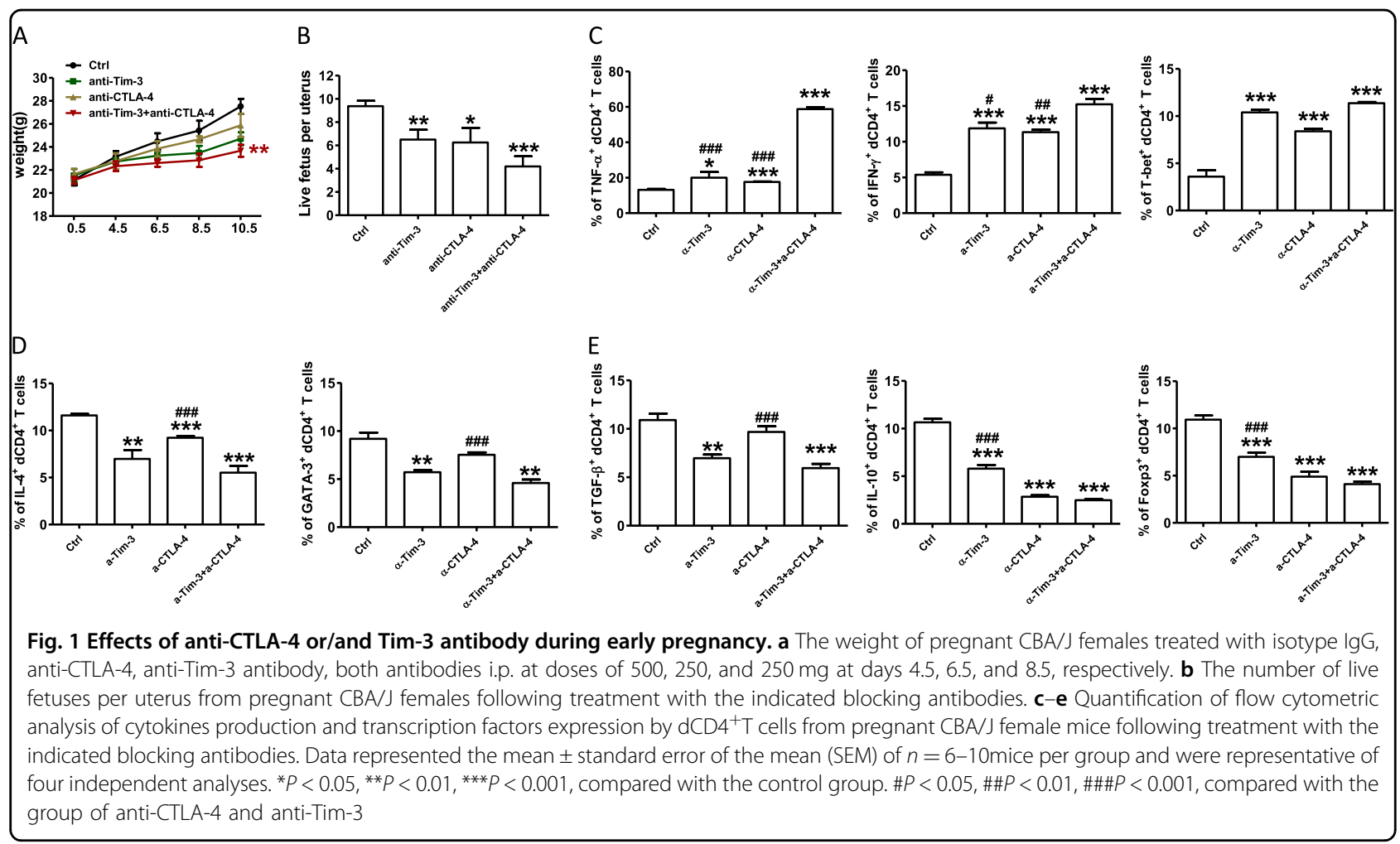

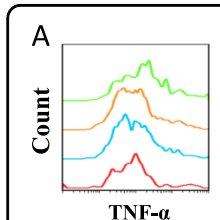

TNF- $\alpha$
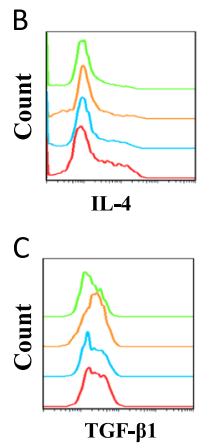
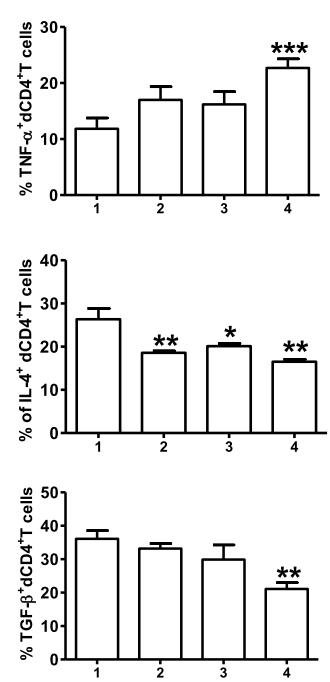

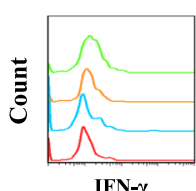

IFN- $\gamma$
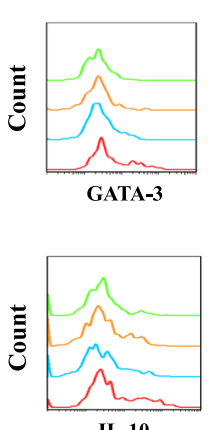

IL-10
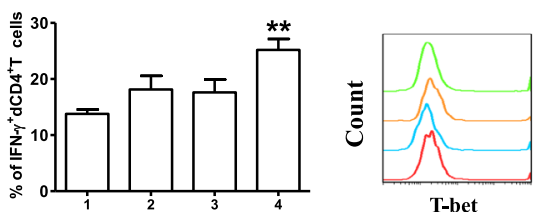

T-bet
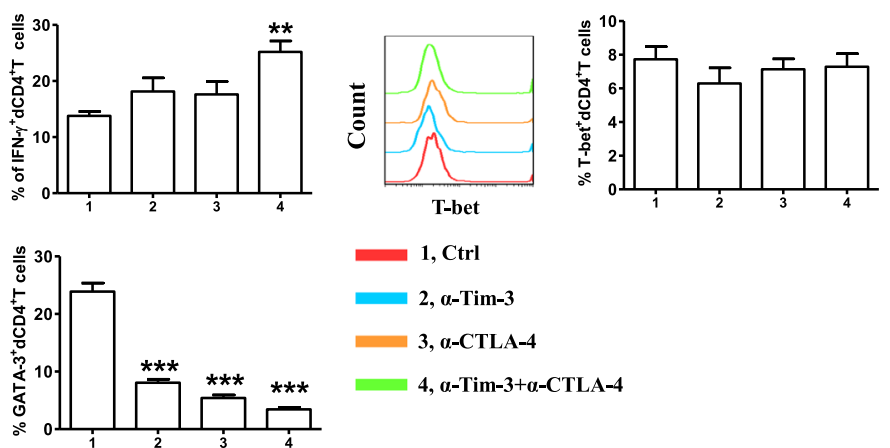

1, Ctrl

2, $\alpha$-Tim-3

3, a-CTLA-4

4, $\alpha$-Tim-3+a-CTLA-4
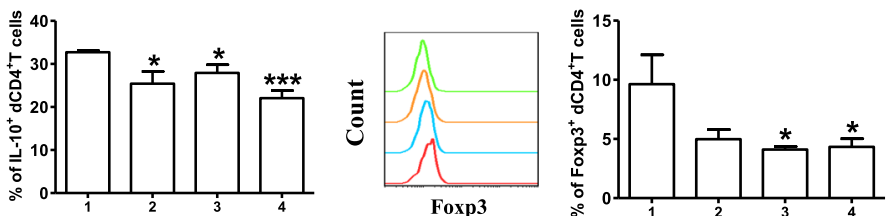

Fig. 2 Effect of blocking CTLA-4 and Tim-3 signaling pathways on cytokines production by human dCD4 ${ }^{+}$T cells. a Expression of Th1-type cytokines and transcription factors of $\mathrm{dCD} 4^{+} \mathrm{T}$ cells cultured for $48 \mathrm{~h}$ in the presence or absence of anti-CTLA-4 antibody (10 $\left.\mu \mathrm{g} / \mathrm{ml}\right)$, anti-Tim-3 antibody $(10 \mu \mathrm{g} / \mathrm{ml})$, or both. b Quantification of flow cytometric analysis of IL-4 and GATA-3 expression by dCD4 ${ }^{+} \mathrm{T}$ cells following treatment with the indicated blocking antibodies. c Expression of Treg-type cytokines by $\mathrm{dCD} 4^{+} \mathrm{T}$ cells following treatment with the indicated blocking antibodies. Data represented the mean \pm SEM. $n=12 .{ }^{*} P<0.05,{ }^{* *} P<0.01,{ }^{* * *} p<0.001$, compared with the control group

$\mathrm{dCD} 4^{+} \mathrm{T}$ cells than in the peripheral $\mathrm{CD} 4^{+} \mathrm{T}\left(\mathrm{pCD} 4^{+} \mathrm{T}\right)$ cells in human early pregnancy. In contrast, a higher number of CTLA- $4^{-}$Tim $-3^{-} \mathrm{CD} 4^{+} \mathrm{T}$ cells were observed in the peripheral blood. In addition, co-culture of
$\mathrm{pCD} 4^{+} \mathrm{T}$ with trophoblasts (Tros) increased the frequency of CTLA-4 and Tim-3 co-expressing cells, while it decreased the frequency of CTLA- $4^{-}$Tim $-3^{-} \mathrm{CD} 4^{+} \mathrm{T}$ cells (Fig. 3b). 
At the maternal-fetal interface, invading placental cells, mainly Tros, maternal-derived decidual stromal cells (DSCs), and decidual immune cells (DICs), come into direct contact with each other ${ }^{8}$. The semi-allogeneic Tros have a unique human leukocyte antigen that expressing a large repertoire of class I HLA-C and nonclassical HLA-G antigens, whereas the class I antigens HLA-A and HLA-B and class II antigens are absent ${ }^{14,15}$. We co-cultured $\mathrm{dCD} 4^{+} \mathrm{T}$ cells with different cell populations to further explore the mechanisms mediating the up-regulation of CTLA- 4 and Tim-3 expression on dCD $4^{+}$T cells (Fig. 3c). We found that primary Tros and HTR8/Svneo cell line (an immortalized human extravillious trophoblast cell line) but not DSCs could raise the co-expression of CTLA- 4 and Tim- 3 on dCD $4^{+}$T cells. Separation of Tros and $\mathrm{dCD} 4^{+} \mathrm{T}$ cells with a transwell insert canceled the promotion of CTLA-4 and Tim-3 co-expression by Tros. Interestingly, administration of anti-HLA-C antibody, but not anti-HLA-G antibody, significantly inhibited Trosinduced up-regulation of CTLA-4 and Tim-3 co-expression on $\mathrm{dCD} 4^{+} \mathrm{T}$ cells.

\section{Characterization of dCTLA $-4^{+} \mathrm{Tim}-3^{+} \mathrm{CD} 4^{+} \mathrm{T}$ cells during human early pregnancy}

Based on CD45RA, CCR7, and CD27 expression, $\mathrm{CD} 4^{+} \mathrm{T}$ cells can be classified as naive $\mathrm{T}$ cells $\left(\mathrm{CD} 27^{+} \mathrm{CD} 45 \mathrm{RA}^{+} \mathrm{CCR} 7^{+}\right)$, central memory $\mathrm{T}$ cells $\left(\mathrm{T}_{\mathrm{CM}}\right.$, $\left.\mathrm{CD} 45 \mathrm{RA}^{-} \mathrm{CD} 27^{+} \mathrm{CCR}^{+}\right)$, memory $\mathrm{T}$ cells $\left(\mathrm{T}_{\mathrm{M}}\right.$, $\left.\mathrm{CD} 4 \mathrm{RA}^{-} \mathrm{CD} 27^{+} \mathrm{CCR}^{-}\right), \mathrm{T}_{\text {Int }}\left(\mathrm{CD} 45 \mathrm{RA}^{+} \mathrm{CD} 27^{\mathrm{dim}^{-} \mathrm{CCR} 7^{-}}\right)$, effector memory $\mathrm{T}$ cells $\left(\mathrm{T}_{\mathrm{EM}}, \mathrm{CD} 45 \mathrm{RA}^{-} \mathrm{CCR} 7^{-} \mathrm{CD} 27^{-}\right)$, and effector memory $\mathrm{T}$ cells that express CD45RA cells (EMRA, CD45RA $\left.{ }^{+} \mathrm{CD}_{27}{ }^{-} \mathrm{CCR}^{-}\right)^{16}$. Compared to dCTLA-4-Tim- $-3^{-} \mathrm{CD} 4^{+} \mathrm{T}$ cells, a significant portion of dCTLA $-4^{+}$Tim- $3^{+} \mathrm{CD} 4^{+} \mathrm{T}$ cells was identified in the naive $\mathrm{T}$ cell subset (Fig. 4a), while the concentrations of dCTLA $-4^{+}$Tim- $3^{+} \mathrm{CD} 4^{+} \mathrm{T}$ cells were lower in central memory and other effector cells. Along with this, the expression of $\mathrm{CD} 127$ (as $\mathrm{CD} 4^{+} \mathrm{T}$ cells differentiate, they lose expression of CD127) was higher, but the activation marker CD69 was lower in dCTLA-4 $4^{+}$ Tim $-3^{+} \mathrm{CD} 4^{+} \mathrm{T}$ cells (Fig. 4b). This dCTLA- $4^{+}$ Tim $-3^{+} \mathrm{CD} 4^{+} \mathrm{T}$ cell subset was more likely to survive at the maternal-fetal interface as confirmed by the higher expression of ki67 (Fig. 4c).

It has been observed that production of proinflammatory or anti-inflammatory cytokines by $\mathrm{CD} 4{ }^{+} \mathrm{T}$ cells at the maternal-fetal interface could influence the fate of pregnancy ${ }^{17}$. Next, we evaluated whether dual CTLA-4 and Tim-3 expression correlated with the $\mathrm{dCD} 4^{+} \mathrm{T}$ cells function of producing cytokines. We found that the production of pro-inflammatory cytokines (TNF$\alpha$, IFN- $\gamma$, and IL-17A) by dCTLA- $4^{+}$Tim- $3^{+} \mathrm{CD} 4^{+} \mathrm{T}$ cells was lower than that by dCTLA- $4^{-}$Tim $-3^{-} \mathrm{CD} 4^{+} \mathrm{T}$ cells (Fig. 5a). Additionally, dCTLA $-4^{+}$Tim $-3^{+} \mathrm{CD} 4^{+} \mathrm{T}$ cells are associated with increased Th2-type and Treg-type cytokines production (Fig. 5b). We then examined the expression of master transcription factors associated with Th1/Th2/Treg/Th17 cells. As shown in Fig. 5c, dCTLA $-4^{+}$Tim $-3^{+} \mathrm{T}$ cells exhibited significantly higher GATA-3 and Foxp3, but lower ROR- $\gamma$ t expression. However, the expression of T-bet did not change with the expression of CTLA- 4 and Tim- 3 on $\mathrm{dCD}^{+} \mathrm{T}$ cells. These data gave the first indication that $\mathrm{dCD} 4^{+} \mathrm{T}$ cells characterized by differential expression of CTLA-4 and Tim-3 contained cells in different functional states.

\section{Disorder of the number and function of dCTLA-4 ${ }^{+}$Tim- $3^{+} \mathrm{CD} 4^{+} \mathrm{T}$ cells in miscarriage}

As blockade of CTLA-4 and Tim-3 signals was harmful to the maintenance of normal pregnancy, and dCTLA$4^{+} \mathrm{Tim}-3^{+} \mathrm{CD} 4^{+} \mathrm{T}$ cells were associated with Th2-type and Treg-type cytokines production, we further explored the possible clinical significance of CTLA- 4 and Tim- 3 by analyzing samples from normal pregnant subjects and patients who experienced RSA. Flow cytometric analysis revealed a much lower co-expression of CTLA-4 and Tim-3 on $\mathrm{dCD} 4^{+} \mathrm{T}$ cells from RSA compared with that from normal pregnancy (Fig. 6a). Although the expression of Ki67 and CD127 on dCTLA- $4^{+}$Tim $-3^{+} \mathrm{CD} 4^{+} \mathrm{T}$ cells was stable in RSA, these cells expressed significantly higher levels of CD69 (Fig. 6b). A significant portion of dCTLA $-4^{+}$Tim $-3^{+} \mathrm{CD} 4^{+} \mathrm{T}$ cells was identified in the naive $\mathrm{T}$ cell subset (Fig. 4a) in normal pregnancy. In contrast, the proportion of dCTLA $-4^{+} \mathrm{Tim}-3^{+} \mathrm{CD} 4^{+} \mathrm{T}$ cells in the $\mathrm{T}_{\text {Naive }}$ subset was limited from RSA, but was greater in the $\mathrm{T}_{\mathrm{EM}}$ subset (Fig. 6c). In addition, dCTLA-4 ${ }^{+}$Tim$3^{+} \mathrm{CD}^{+} \mathrm{T}$ cells from RSA expressed higher levels of TNF- $\alpha$, IFN- $\gamma$, IL-17A, T-bet, and ROR- $\gamma$ t (Fig. $6 \mathrm{~d}$, f), but lower amounts of IL-4, TGF- $\beta 1$, GATA-3, and Foxp3 (Fig. 6e, f). We could not detect the difference in IL-10 expression on dCTLA- $4^{+}$Tim $-3^{+} \mathrm{CD} 4^{+} \mathrm{T}$ between normal pregnancy and RSA (Figure S3). We also observed fewer dCTLA $-4^{+}$Tim $-3^{+} \mathrm{CD} 4^{+} \mathrm{T}$ cells and higher expression of Th1-type cytokines, but lower Th2-type and Treg-type cytokines by dCTLA- $4^{+} \mathrm{Tim}-3^{+} \mathrm{CD} 4^{+} \mathrm{T}$ cells in female $\mathrm{CBA} / \mathrm{J}$ mated with male DBA/2 mice, a well-established model of abortion (Fig. 7).

\section{Discussion}

There is evidence that $\mathrm{T}$ cells lose their effector functions on chronic stimulation by tumors or virus antigens, which is accompanied by aprogressive increase in the inhibitory receptors expressed on them, including CTLA4 and Tim- $3^{18}$. Given that Tim-3 negatively regulates IFN- $\gamma$-mediated Th1 responses, the use of anti-Tim-3 antibody may complement therapies (like anti-CTLA-4 antibody) relieving $\mathrm{T}$ cell anergy/exhaustion/tolerance pathways $^{19}$. At the 2010 American Society of Clinical 


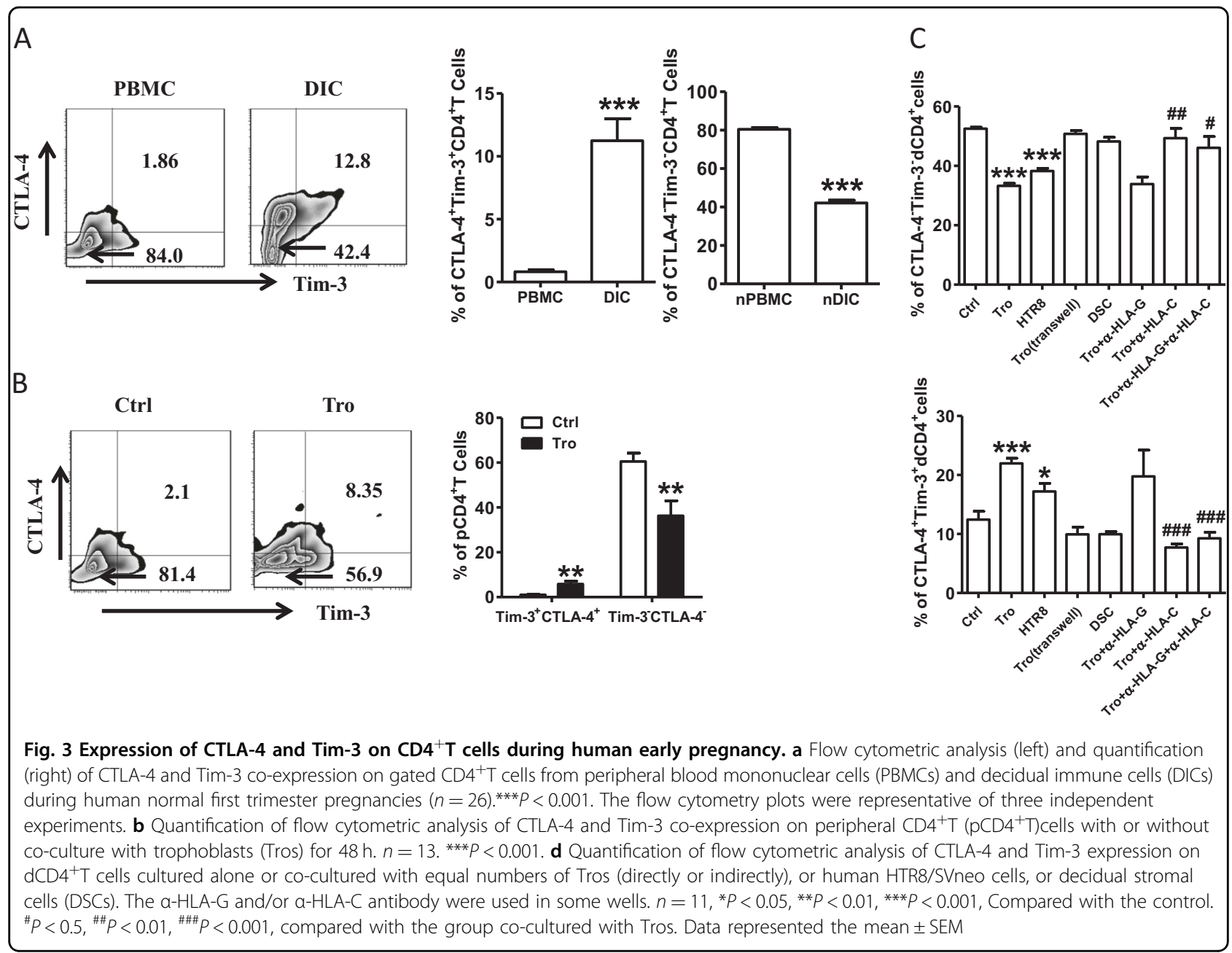

Oncology Annual Meeting, ipilimumab(an anti-human CTLA-4 antibody) was reported to extend the overall survival in patients with advanced melanoma by 10months, and an important study showed considerable therapeutic benefit in combining anti-CTLA-4 and antiTim-3 to control CT26 colon adenocarcinoma ${ }^{20}$. Combination therapies were thought to be a promising novel therapeutic approach for several types of human malignancies ${ }^{13}$. Iilimumab was categorized as pregnancy category $\mathrm{C}$ by the United States Food and Drug Administration ${ }^{21}$, due to the less clear role of the CTLA-4 axis in fetal immunity. One anti-Tim-3 mAb is being investigated in a phase I-II clinical trial, but no clinical results have yet been reported ${ }^{13}$. The purpose of the present study was to examine whether blocking these inhibitory pathways affected the outcome of pregnancy and determine whether CTLA-4 and Tim-3 pathways were involved in the establishment and maintenance of maternal-fetal tolerance.

Pregnant CBA/J females treated with Tim-3-and/or CTLA-4-blocking antibodies became more susceptible to fetal loss (Fig. 1), although the further development of any surviving embryos needs additional study. With unknown risks of harm to mothers and the potential of birth defects, use of CTLA-4 and/or Tim-3 blockade agents in pregnancy would likely pose great risk of abortion, and it would ultimately be an individualized decision made with careful consideration of potential benefits and risks.

Upon encountering antigens displayed by antigen presenting cells or being driven by a set of cytokines, naive $\mathrm{CD} 4^{+} \mathrm{T}$ cells can differentiate into distinct subsets, including Th1, Th2, Th17, and Treg cells. Their differentiation is controlled by the following lineage-specific master transcription factors: T-bet for Th1, GATA-3 for Th2, ROR-yt for Th17, and Foxp3 for Treg ${ }^{22,23}$. The production of pro- or anti-inflammatory cytokines at the maternal-fetal interface influences the outcome of pregnancy because there is dominance by Th2-type and Tregtype cytokines (IL-4, IL-10, TGF- $\beta 1$ ) during normal pregnancy and dominance by Th1-type cytokines in miscarriage ${ }^{8,24}$. For example, committed Th1 polarization blocking Treg differentiation triggers antigen specific fetal 


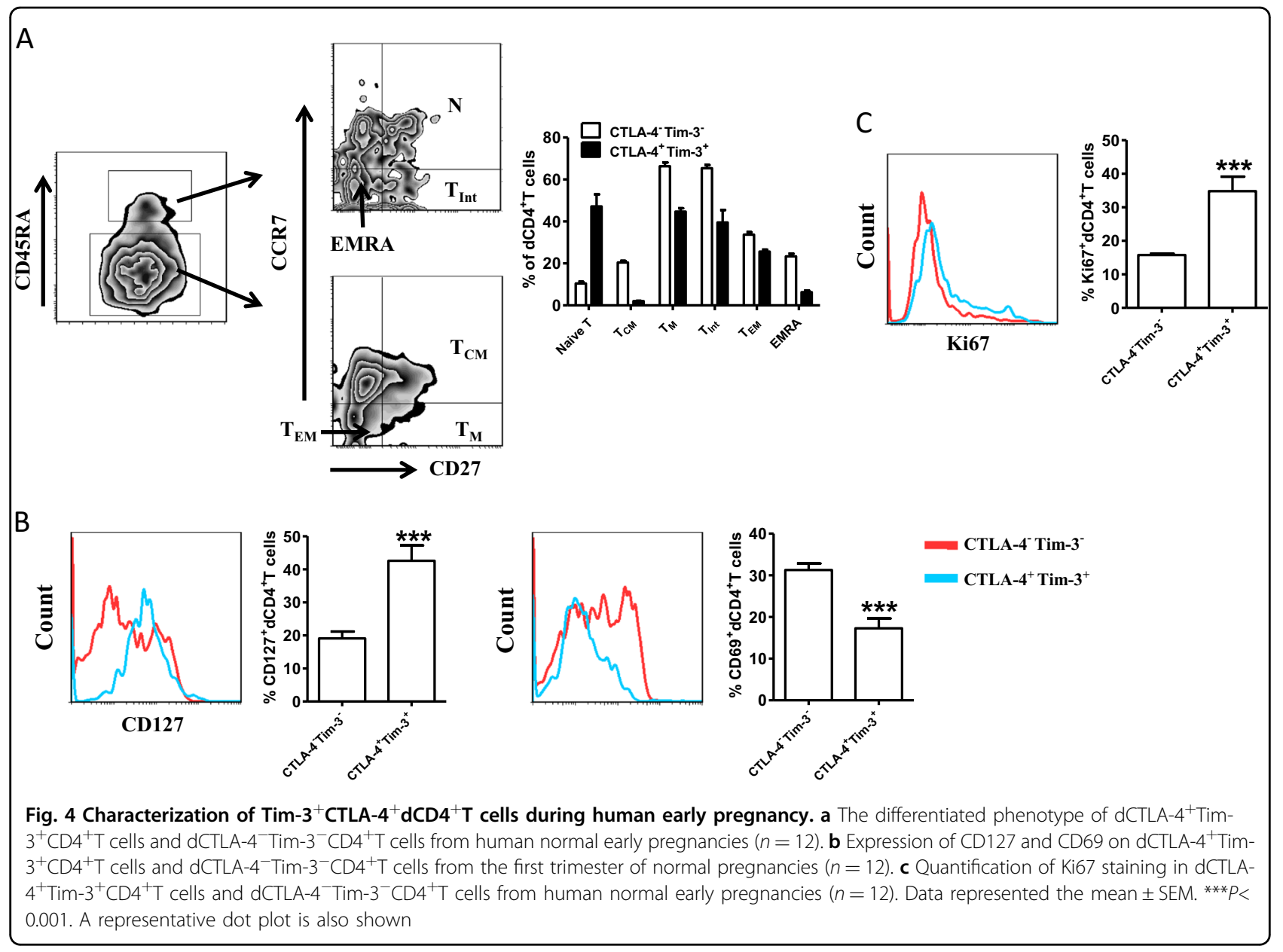

$\operatorname{loss}^{25}$. We found that single or combination of CTLA-4 and Tim-3 blockade resulted in a decreased production of Th2-type and Treg-type cytokines, but it increased Th1type cytokines of $\mathrm{dCD} 4^{+} \mathrm{T}$ cells both in vivo and in vitro. These data indicate that fetal loss induced by CTLA-4 and/or/ Tim-3 blockade maybe associated with the dysfunction of $\mathrm{CD} 4^{+} \mathrm{T}$ cells by the production of disordered cytokines.

$\mathrm{CD} 4{ }^{+} \mathrm{T}$ cells are thought to play a pivotal role in inducing and maintaining maternal-fetal tolerance, and for controlling maternal viremia ${ }^{26}$. However, the mechanism that regulates $\mathrm{CD}^{+} \mathrm{T}$ cell response during pregnancy remains to be explored. We found CTLA- 4 and Tim-3 were expressed on significantly higher proportions of $\mathrm{dCD} 4^{+} \mathrm{T}$ cells than $\mathrm{pCD} 4^{+} \mathrm{T}$ cells. In addition, Tros contribute to the expansion of dCTLA- $4^{+} \mathrm{Tim}-3^{+} \mathrm{CD} 4^{+} \mathrm{T}$ cells depending on HLA-C in a direct contact manner. Furthermore, dCTLA $-4^{+} \mathrm{Tim}-3^{+} \mathrm{CD} 4^{+} \mathrm{T}$ cells possessed higher proliferative capability and produced more Th2cytokines and Treg cytokines to further promote maternalfetal tolerance. Tros, not DSCs, up-regulated the percentage of dCTLA $-4^{+} \mathrm{Tim}-3^{+} \mathrm{CD} 4^{+} \mathrm{T}$ cells, providing further evidence that embryonic Tros have the unique ability to instruct DICs to develop a regulatory phenotype for fetal tolerance. Our data also confirmed that HLA-C expressed on Tros was involved in the regulation of $\mathrm{dCD} 4^{+} \mathrm{T}$ cells function, in addition to eliciting a direct cytotoxic response by $\mathrm{CD}^{+} \mathrm{T}$ cells ${ }^{27,28}$. CTLA- 4 and Tim-3 are well-known inhibitory co-stimulatory signals that contribute to the exhaustion of $\mathrm{T}$ cells ${ }^{18}$. Based on their predicted ability to survive and proliferate, $\mathrm{T}$ cell subpopulations can be ranked (from highest to lowest) as follows: Naive $\rightarrow$ $\mathrm{T}_{\mathrm{CM}} \rightarrow \mathrm{T}_{\mathrm{M}} \rightarrow \mathrm{T}_{\text {Int }} \rightarrow \mathrm{T}_{\mathrm{EM}} \rightarrow \mathrm{EMRA}^{29}$. Our results indicated that CTLA-4 and Tim-3 co-expression demarcated a $\mathrm{T}_{\text {Naive }}$ phenotypic signature that favored persistence compared to dCTLA- $4^{-}$Tim $-3^{-}$CD $4^{+} \mathrm{T}$ cells. Differentiation of $T$ cells into effector cells during primary immune responses has important consequences for the development of active immunity, the proportion of $\mathrm{T}_{\mathrm{EM}}$ subset was higher in dCTLA $-4^{+}$Tim $-3^{+} \mathrm{CD} 4^{+} \mathrm{T}$ cells in RSA (Fig. 6c). Along with this, the production of Th1- and Th17-type cytokines by dCTLA $-4^{+}$Tim $-3^{+} \mathrm{CD} 4^{+} \mathrm{T}$ cells also increased in RSA. There was compelling evidence showing an alteration of Th1/Th2/Th17 and Treg cells subsets in unexplained 


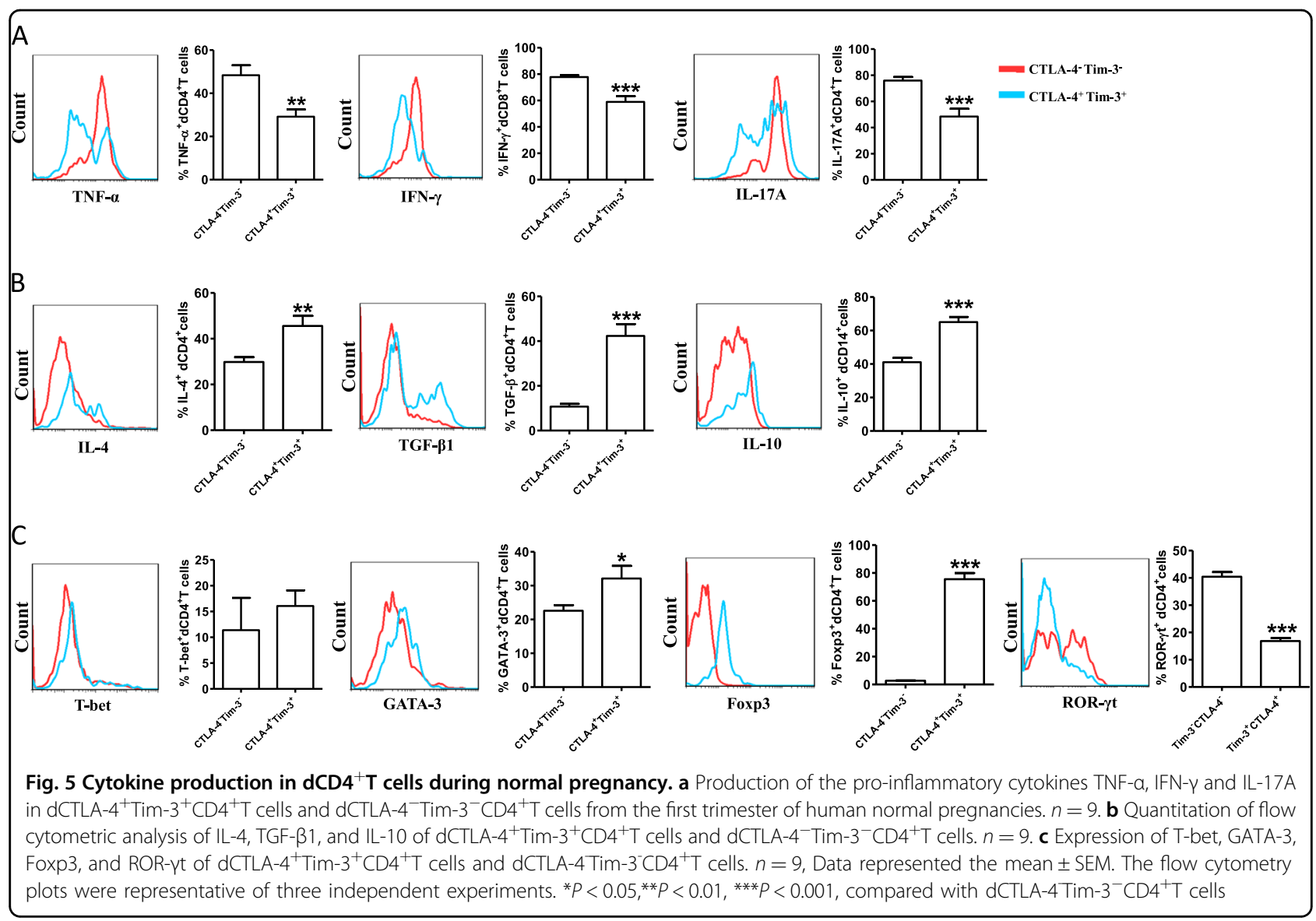

recurrentmiscarriages ${ }^{30}$. Together with the decreased cell number, proliferation and anti-inflammatory production by $\mathrm{dCTLA}-4^{+} \mathrm{Tim}-3^{+} \mathrm{CD} 4^{+} \mathrm{T}$ cells in RSA, CTLA-4, and $\mathrm{Tim}-3$ pathways were associated with $\mathrm{dCD} 4^{+} \mathrm{T}$ cell function and pregnancy outcome. Though the expression of IL-17A and ROR- $\gamma \mathrm{t}$ varied in the dCTLA- $4^{+}$Tim $-3^{+} \mathrm{CD} 4^{+} \mathrm{T}$ cells and dCTLA- $4^{-}$Tim$3^{-} \mathrm{CD} 4^{+} \mathrm{T}$ cells, Th17-type cytokines possessed weak reactivity to CTLA-4 and/or Tim-3 blockade. Thus, Th17 immune responses may not function along with CTLA-4 and Tim-3 during pregnancy.

The single and/or combination use of immune checkpoint blockade therapies in human infectious diseases and cancer is rapidly expanding ${ }^{1}$. The results of the current study show that CTLA-4 and Tim-3 pathways appear to play key roles in maintaining maternal-fetal tolerance by regulating the function of $\mathrm{dCD} 4^{+} \mathrm{T}$ cells. The abnormality in number and functionality of dCTLA-4 ${ }^{+}$Tim$3^{+} \mathrm{CD} 4^{+} \mathrm{T}$ cells is at least one of the reasons leading to the occurrence of miscarriage. In animal studies, antiCTLA-4/Tim-3 antibody clearly increases the risks of abortion. Thus, characterizing the efficacy and safety of anti-CTLA-4/Tim-3 antibody (and other immune checkpoint inhibitors) in different patient populations is a critical objective. Reproductive safety must be considered, especially when these therapies are used during pregnancy.

\section{Materials and methods Mice}

$\mathrm{CBA} / \mathrm{J}$ female, DBA/2 male, and BALB/c male mice were purchased from Huafukang (Beijing, China). All of the animals were conducted in accordance with the National Guidelines for Animal Care and Use in Research (China). The experimental methods in particular were carried out in accordance with the approved guidelines. Eight-week-old CBA/J females were mated to BALB/c males to induce normal pregnancies, $\mathrm{CBA} / \mathrm{J}$ females were mated to DBA/2 males to establish abortion-prone models, and inspected every morning for vaginal plugs. The day of visualization of a plug was designated as day 0.5 of pregnancy. In some experiments, pregnant females received injections of single or combined anti-CTLA-4 antibody (clone 9H10, BioLegend, U.S.A.), anti-Tim-3 antibody (clone RMT3-23, BioLegend, U.S.A.), or isotype IgG; i.p. at doses of 500, 250, and $250 \mathrm{mg}$ on days $4.5,6.5$, and 8.5 , respectively, based on our previous publications $^{31,32}$. All pregnant mice were monitored at day 10.5 of pregnancy. 


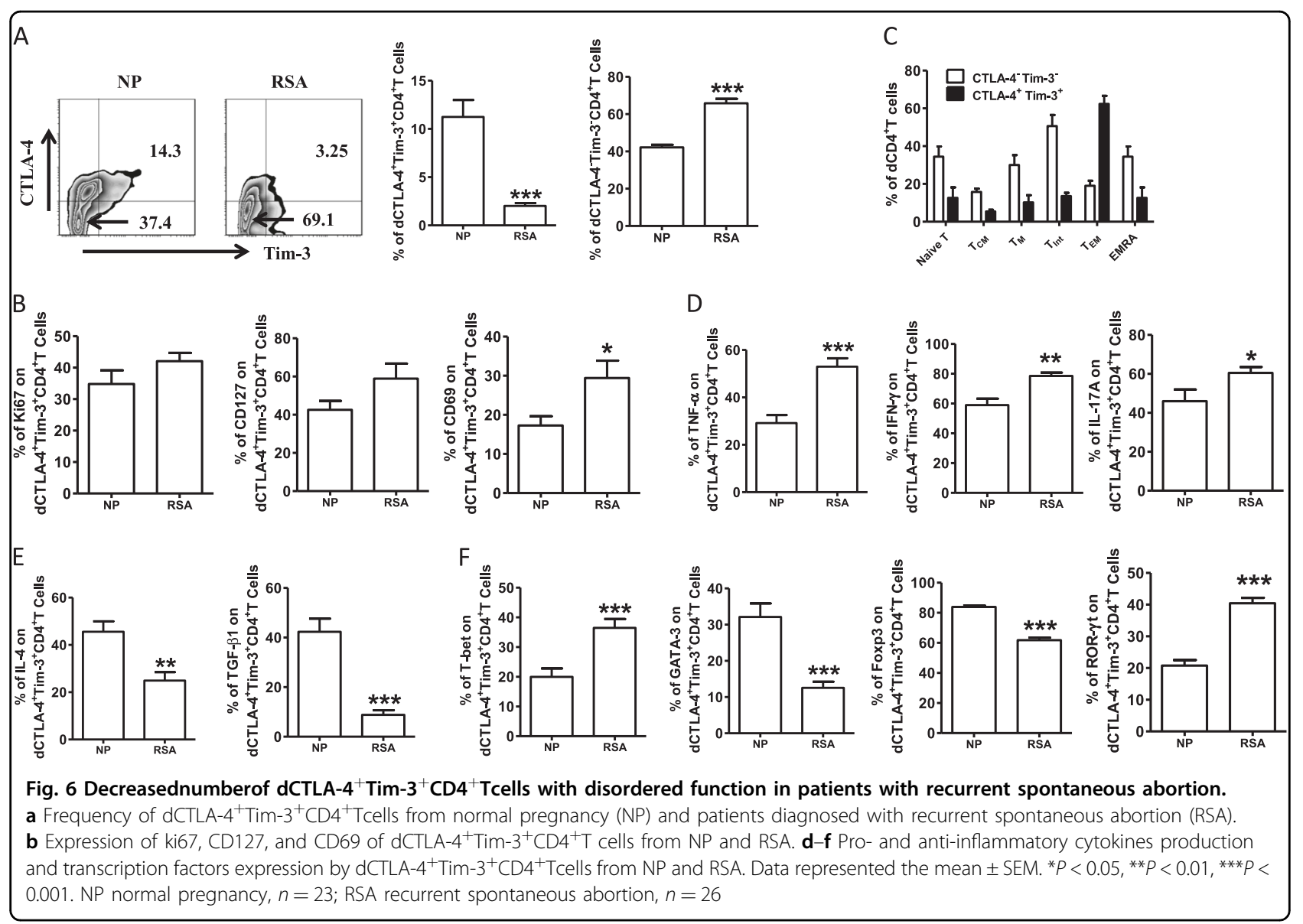

\section{Preparation of mouse cells}

Uteri from pregnant mice were dissected free from the mesometrium and the fetal and placental tissues were carefully removed from the uterus. Washed and Minced uteri were digested in RPMI 1640 (HyClone, U.S.A.) supplemented with collagenase type IV $(1.0 \mathrm{mg} / \mathrm{ml}$, Worthington Biomedical, U.S.A.) and DNase I (150 U/ml, Applichem, Germany) for $30 \mathrm{~min}$ at $37^{\circ} \mathrm{C}$ with gentle agitation. Cells were cultured in RPMI 1640 supplemented with $10 \% \mathrm{FBS}, 100 \mathrm{U} / \mathrm{ml}$ penicillin, $100 \mu \mathrm{g} / \mathrm{ml}$ streptomycin, and $1 \mu \mathrm{g} / \mathrm{ml}$ amphotericin $\mathrm{B}$ at $37^{\circ} \mathrm{C}$ in $5 \%$ $\mathrm{CO}_{2}$ for $2 \mathrm{~h}$ to remove adherent stromal cells. Then the cell suspensions were collected and Phorbol 12-myrstate 13-acetate (PMA) (50 ng/ml, BioLegend, U.S.A.), ionomycin $(1 \mu \mathrm{g} / \mathrm{ml}$, Biolegend, U.S.A.) and brefeldin A $(10 \mathrm{mg} / \mathrm{ml}$, BioLegend, U.S.A.) were added in the culture for $4 \mathrm{~h}$ for intracellular cytokine analysis.

\section{Human samples}

This study was approved by the Human Research Ethics Committee of the Obstetrics and Gynecology Hospital, Fudan University. Every participant signed a written informed consent form. Samples of human firsttrimester pregnancies were obtained from clinically normal pregnancies (terminated for non-medical reasons, $N=72$, whole peripheral blood, villous and decidual tissues) and miscarriages (diagnosed as recurrent spontaneous abortion, RSA, and excluding those resulted from chromosomal defects, endocrine, anatomic, genetic abnormalities, infection, etc., $N=26$, decidual tissues). Samples were immediately collected for the isolation of peripheral blood mononuclear cells (PBMCs), Tros, DSCs, and DICs.

\section{Human cell isolation}

PBMCs were isolated from peripheral blood samples of normal pregnancies using Ficoll density gradient centrifugation (Huajing, China). Tros were isolated from the normal placenta tissues by trypsin-DNase I $(150 \mathrm{U} / \mathrm{ml}$, Applichem, Germany) digestion and discontinuous Percoll gradient centrifugation (GE Healthcare, U.S.A.). DICs and DSCs were obtained from the normal or RSA decidual tissue digesting in RPMI 1640 (HyClone, U.S.A.) supplemented with collagenase type IV $(1.0 \mathrm{mg} / \mathrm{ml}$, CLS1, Worthington Biomedical, U.S.A.) and DNase I (150 U/ $\mathrm{ml}$, Applichem, Germany) as described previously ${ }^{31,33}$. $\mathrm{CD} 4{ }^{+} \mathrm{T}$ cells were isolated by magnetic affinity cell sorting using CD4 microbeads (MiltenyiBiotec, Germany). 


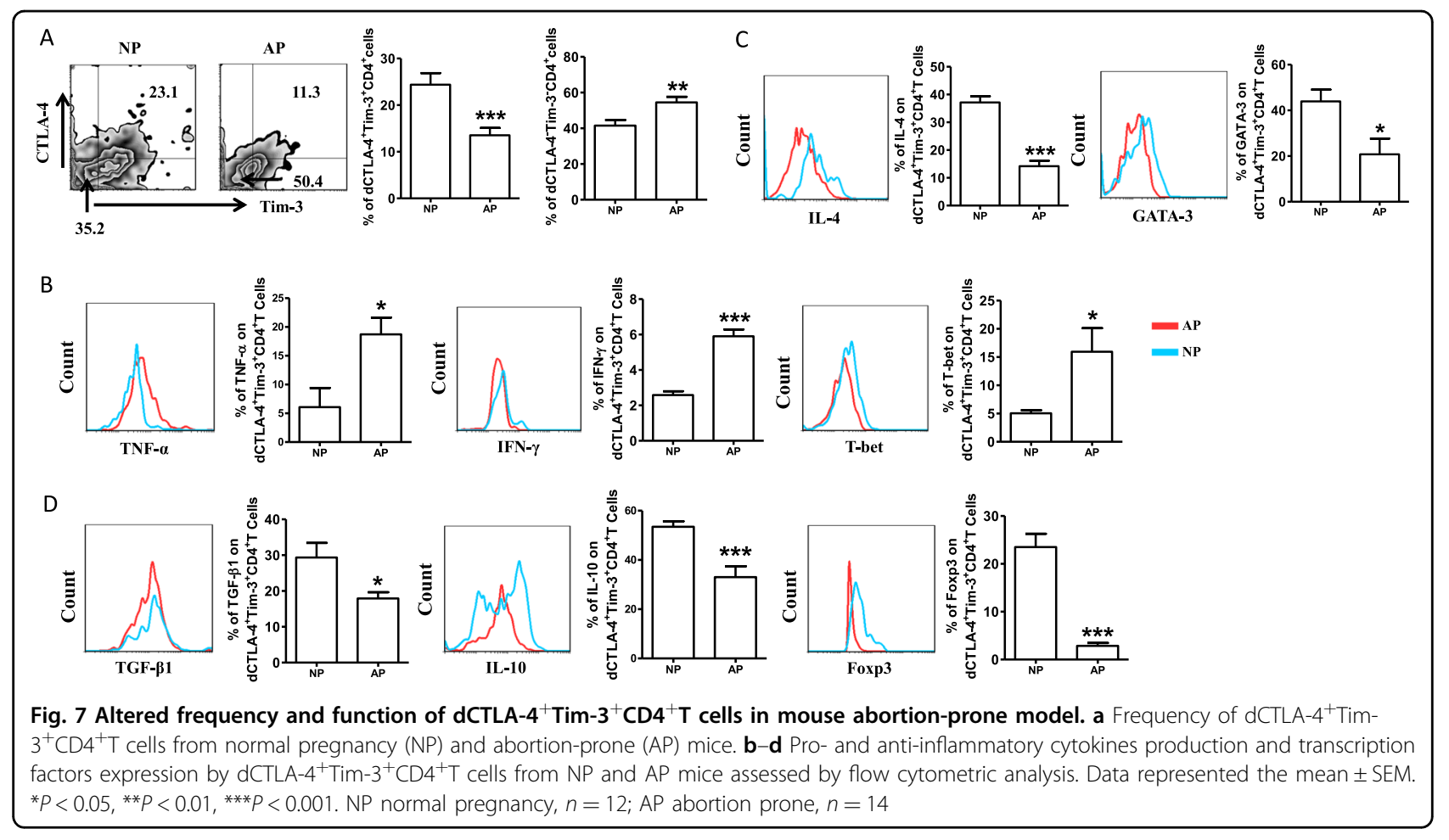

\section{Co-culture of $\mathrm{CD}^{+}{ }^{+} \mathrm{T}$ cells and other cells}

Freshly isolated Tros (Matrigel-coated 24-well plates) or HTR8/SVneo cells, or DSCs were seeded at a density of $2 \times 10^{5}$ cells $/ \mathrm{ml}$ per well in 24-well plates overnight. The cells were then washed with PBS (HyClone, U.S.A.). Equal numbers of $\mathrm{dCD} 4^{+} \mathrm{T}$ cells or $\mathrm{pCD} 4^{+} \mathrm{T}$ cells were added to each well. In some wells, $\mathrm{dCD} 4^{+} \mathrm{T}$ cells were plated in the upper chamber $(0.4 \mathrm{~mm}$ poresize cell culture inserts, Millipore, Germany), while Tros were plated in the lower chamber to establish indirect cell contact. In some wells, anti-HLA-G $(10 \mu \mathrm{g} / \mathrm{ml}$, clone $87 \mathrm{G}$; Biolegend, U.S.A.) or/and anti-HLA-C $(10 \mu \mathrm{g} / \mathrm{ml}$, clone W6/32; Biolegend, U.S.A.) were added. PMA $(50 \mathrm{ng} / \mathrm{ml})$, ionomycin $(1 \mu \mathrm{g} / \mathrm{ml})$ and brefeldin A $(10 \mathrm{mg} / \mathrm{ml})$ were added $4 \mathrm{~h}$ before the end of the $48 \mathrm{~h}$ culture for intracellular cytokine analysis. The immune cells were then harvested for flow cytometry analysis.

\section{CTLA-4 and Tim-3 targeting experiments}

$\mathrm{dCD} 4^{+} \mathrm{T}$ cells were cultured $\left(5 \times 10^{5}\right.$ per well $)$ in the presence of anti-CTLA-4 $(10 \mu \mathrm{g} / \mathrm{ml}$, clone L3D10, BioLegend, U.S.A.), anti-Tim-3 (10 $\mu \mathrm{g} / \mathrm{ml}$, clone F38-2E2, BioLegend, U.S.A.), both of the two antibodies, or isotype control for $48 \mathrm{~h}$. Brefeldin A, PMA, and ionomycin was added $4 \mathrm{~h}$ before the end of the culture. The cells were then collected for further analysis by flow cytometry.

\section{Flow cytometry}

Cell surface molecular expression and intracellular cytokines production were evaluated using flow cytometry. FITC-conjugated anti-human or anti-mouse CD4, AlexaeFluor $^{\circledR} 488$ - conjugated anti-human or anti-mouse Foxp3, IFN- $\gamma$, PE-conjugated anti-human Tim-3, or antimouse Tim-3, T-bet or GATA-3, PE/CY7-conjugated anti-human IL-10, TNF- $\alpha$, IFN- $\gamma$, IL-17A, TGF- $\beta 1$ or CD45RA, PerCP/Cy5.5-conjugated anti-human CCR7, PerCP/Cy5.5-conjugated anti-mouse GATA-3, T-bet, or IL-17A, APC-conjugated anti-human CTLA-4, GATA-3, or anti-mouse CTLA-4, TNF- $\alpha$, IL-10 or GATA-3, Brilliant Violet 421-conjugated anti-human CD27, Ki-67, ROR- $\gamma \mathrm{t}$, or IL-4, or anti-mouse CD4, Tim-3, IFN- $\gamma$, IL-4, or TGF- $\beta 1$, Brilliant Violet 510-conjugated anti-human CD4, anti-mouse TNF- $\alpha$, IL-4 or IFN- $\gamma$ antibodies (Biolegend, U.S.A.) were used. For intracellular staining, cells were fixed and permeabilized using the Fix/Perm kit (Biolegend, U.S.A.). Flow cytometry was performed on a Beckman-Coulter CyAn ADP cytometer and analyzed with FlowJo software (Tree Star, U.S.A.).

\section{Statistical analysis}

The statistical significance of differences between two groups was determined by the post-hoc Dunnett $t$-test. Multiple groups were analyzed with GraphPad Prism Version 7 by one-way or two-way ANOVA with 
Bonferroni post $t$-tests. For all statistical tests, $p$ values $<$ 0.05 were considered statistically significant.

\section{Acknowledgements}

This work was supported by grant from the Nature Science Foundation from National Nature Science Foundation of China (NSFC) (81630036, 91542116 and 31570920 to MRD, 31700799 to S.C.W.), the National Basic Research Program of China (2015CB943300 to D.J.L. and M.R.D.), the National Key R\&D Program of China (2017YFC1001403 to D.J.L. and M.R.D.), the Program of Shanghai Academic/Technology Research Leader (17XD1400900 to M.R.D.),the Innovation-oriented Science and Technology Grant from NHC Key Laboratory of Reproduction Regulation (CX2017-2 to M.R.D. and D.J.L.), the Shanghai Sailing Program (17YF1411600 to S.C.W.), the Training Program for Young Talents of Shanghai Health System (2018YQ07 to S.C.W.), Development Fund of Shanghai Talents (2018110 to S.C.W.), and the Introduction Project of Suzhou Clinical Medicine Expert Team (grant SZYJTD201708 to R.Z. and D.J.L.).

\section{Author details}

'Laboratory for Reproductive Immunology, NHC Key Lab of Reproduction Regulation(Shanghai Institute of Planned Parenthood Research), Shanghai Key Laboratory of Female Reproductive Endocrine Related Diseases, Hospital of Obstetrics and Gynecology, Fudan University Shanghai Medical College, Shanghai, P.R. China. ${ }^{2}$ Reproductive Medicine Center, Hospital of Obstetrics and Gynecology, FudanUniversity Shanghai Medical School, Shanghai, P.R. China. ${ }^{3}$ Department of Clinical Laboratory, Hospital of Obstetrics and Gynecology, Fudan University, Shanghai, P.R. China. ${ }^{4}$ Department of Medicine, Montefiore Medical Center, Albert Einstein College of Medicine, Bronx, NY, USA. ${ }^{5}$ The Affiliated Suzhou Hospital of Nanjing Medical University/Suzhou Municipal Hospital, Suzhou 215008, China

\section{Conflict of interest}

The authors declare that they have no conflict of interest.

\section{Publisher's note}

Springer Nature remains neutral with regard to jurisdictional claims in published maps and institutional affiliations.

Supplementary Information accompanies this paper at (https://doi.org/ 10.1038/s41419-018-1251-0).

Received: 18 September 2018 Revised: 11 November 2018

Accepted: 20 November 2018

Published online: 08 January 2019

\section{References}

1. Zhou, G. et al. Antibodies against immune checkpoint molecules restore functions of tumor-infiltrating $T$ cells in hepatocellular carcinomas. Gastroenterology 153, 1107-1119 (2017).

2. Hodi, F. S. et al. Improved survival with ipilimumab in patients with metastatic melanoma. N. Engl. J. Med. 363, 711-723 (2010).

3. Sasso, E. et al. Massive parallel screening of phage libraries for the generation of repertoires of human immunomodulatory monoclonal antibodies. MabsAustin, 10, 1060-1072 (2018).

4. Kudo, M. Immuno-Oncology in Hepatocellular Carcinoma: 2017 Update. Oncol.-Basel 93(Suppl 1), 147-159 (2017).

5. KD, M. \& Le Gros-G. The role of CTLA-4 in the regulation of $T$ cell immune responses. Immunol. Cell Biol., 77,1-10 (1999).

6. Zhu, C. et al. The Tim-3 ligand galectin-9 negatively regulates $T$ helper type 1immunity. Nat. Immunol. 6, 1245-1252 (2005).

7. Ferretti, C., Bruni, L., Dangles-Marie, V., Pecking, A. P. \& Bellet, D. Molecular circuits shared by placental and cancer cells, and their implications in the proliferative, invasive and migratory capacities of trophoblasts. Hum. Reprod. Update 13, 121-141 (2007).

8. Arck, P. C. \& Hecher, K. Fetomaternal immune cross-talk and its consequences for maternal and offspring's health. Nat. Med 19, 548-556 (2013).
9. Zeng, W. et al. Distinct transcriptional and alternative splicing signatures of decidual CD4(+) T cells in early human pregnancy. Front Immunol. 8, 682 (2017).

10. Chaouat, G. et al. Reproductive immunology 2003: reassessing the Th1/Th2 paradigm? Immunol. Lett. 92, 207-214 (2004).

11. Liu, Y. et al. Adoptive transfer of Treg cells counters adverse effects of Toxoplasma gondii infection on pregnancy. J. Infect. Dis. 210, 1435-1443 (2014).

12. Comin-Anduix, B., Escuin-Ordinas, H. \& Ibarrondo, F. J. Tremelimumab: research and clinical development. Onco Targets Ther. 9, 1767-1776 (2016).

13. Marin-Acevedo, J. A. et al. Next generation of immune checkpoint therapy in cancer: new developments and challenges. J. Hematol. Oncol. 11, 39 (2018).

14. Tilburgs, T. et al. Human HLA-G+ extravillous trophoblasts: immune-activating cells that interact with decidual leukocytes. Proc. Natl Acad. Sci. USA 112, 7219-7224 (2015).

15. King, A. et al. Surface expression of HLA-C antigen by human extravillous trophoblast. Placenta 21, 376-387 (2000).

16. McMahan, R. H. et al. Tim-3 expression on PD-1+ HCV-specific human CTLs is associated with viral persistence, and its blockade restores hepatocytedirected in vitro cytotoxicity. J. Clin. Invest. 120, 4546-4557 (2010).

17. La Rocca, C., Carbone, F., Longobardi, S. \& Matarese, G. The immunology of pregnancy: regulatory $T$ cells control maternal immune tolerance toward the fetus. Immunol. Lett. 162, 41-48 (2014).

18. Wherry, E. J. T cell exhaustion. Nat. Immunol. 12, 492-499 (2011).

19. Rabinovich, G. A., Gabrilovich, D. \& Sotomayor, E. M. Immunosuppressive strategies that are mediated by tumor cells. Annu. Rev. Immunol. 25, 267-296 (2007).

20. Ngiow, S. F. et al. Anti-TIM3 antibody promotes T cell IFN-gamma-mediated antitumor immunity and suppresses established tumors. Cancer Res. 71, 3540-3551 (2011).

21. Johnson, D. B., Sullivan, R. J. \& Menzies, A. M. Immune checkpoint inhibitors in challenging populations. Cancer-Am. Cancer Soc. 123, 1904-1911 (2017).

22. Crotty, S. Follicular helper CD4 Tcells (TFH). Annu. Rev. Immunol. 29, 621-663 (2011).

23. Liao, W., Lin, J. X. \& Leonard, W. J. IL-2 family cytokines: new insights into the complex roles of IL-2 as a broad regulator of T helper cell differentiation. Curr. Opin. Immunol. 23, 598-604 (2011).

24. Piccinni, M. P. et al. Defective production of both leukemia inhibitory factor and type 2 T-helper cytokines by decidual T cells in unexplained recurrent abortions. Nat. Med. 4, 1020-1024 (1998).

25. Xin, L. et al. Cutting edge: committed Th1 CD4+ T cell differentiation blocks pregnancy-induced Foxp3 expression with antigen-specific fetal loss. J. Immunol1 92, 2970-2974 (2014).

26. Bialas, K. M. et al. Maternal CD4+ T cells protect against severe congenital cytomegalovirus disease in a novel nonhuman primate model of placental cytomegalovirus transmission. Proc. Natl Acad. Sci. USA 112, 13645-13650 (2015).

27. Tilburgs, T. et al. Fetal-maternal HLA-C mismatch is associated with decidual T cell activation and induction of functional $T$ regulatory cells. J. Reprod. Immunol. 82, 148-157 (2009).

28. Heemskerk, M. B. et al. Allogeneic MHC class I molecules with numerous sequence differences do not elicit a CTL response. Hum. Immunol. 66, 969-976 (2005)

29. Burgers, W. A. et al. Association of HIV-specific and total CD8+ T memory phenotypes in subtype C HIV-1 infection with viral set point. J. Immunol. 182, 4751-4761 (2009)

30. Saito, S., Nakashima, A., Shima, T. \& Ito, M. Th1/Th2/Th17 and regulatory T-cell paradigm in pregnancy. Am. J. Reprod. Immunol. 63, 601-610 (2010).

31. Wang, S. et al. Programmed cell death-1 (PD-1) and T-cell immunoglobulin mucin-3 (Tim-3) regulate CD4+ T cells to induce type 2 helper T cell (Th2) bias at the maternal-fetal interface. Hum. Reprod. 31, 700-711 (2016).

32. Wang, S. C. et al. PD-1 and Tim-3 pathways are associated with regulatory CD8 + T-cell function in decidua and maintenance of normal pregnancy. Cell Death Dis. 6, e1738 (2015).

33. Wang, S. et al. Tim-3 protects decidual stromal cells from toll-like receptormediated apoptosis and inflammatory reactions and promotes Th2 bias at the maternal-fetal interface. Sci. Rep. 5, 9013 (2015). 